
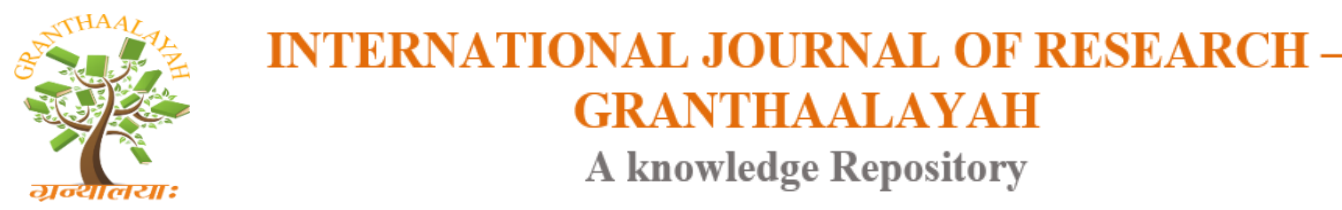

Science

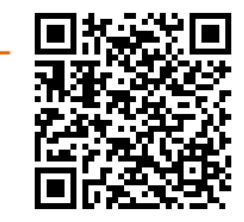

\title{
EFFECTS OF MECHANICAL VIBRATION FORCE ON TOOTH MOVEMENT; FINITE ELEMENT ANALYSIS
}

\author{
Aylin Pasaoglu Bozkurt ${ }^{1}$, Alev Cinsar ${ }^{2}$ \\ ${ }^{1}$ Private Practice, Istanbul, Turkey \\ ${ }^{2}$ Professor, Department of Orthodontics, Faculty of Dentistry, Ege University, Izmir, Turkey
}

\begin{abstract}
Objective: The aim of this finite element study was to assess the effect of mechanical vibration force on tooth movement, stress distribution and velocity.

Methods: A 3D model was created using CBCT image of a patient with class 2 malocclusion. Three different analyses were performed on a single model where upper first premolars were extracted. At canine distalization stage; $150 \mathrm{gf}, 150 \mathrm{gf}$ and $30 \mathrm{~Hz}(0.2 \mathrm{~N}), 150 \mathrm{gf}$ and $111 \mathrm{~Hz}$ $(0.06 \mathrm{~N})$ were applied to canine. The first moment effect of force and vibration were evaluated using the Algor Fempro finite element analysis program. Stress and displacement distribution were investigated comparatively.

Results: It was observed that the maximum displacement occurred in the second analysis (150 gf-30 Hz), while lower displacement was seen in the third analysis $(150 \mathrm{gf}-111 \mathrm{~Hz})$, and the lowest amount of displacement was in the first analysis (150 gf). While only force application caused extrusion of the tooth, linear and vibration forces together caused intrusion. In the first analysis canine rotated in the distovestibule direction, but in the second and third analysis, canine showed distopalatal rotation.
\end{abstract}

Conclusion: It was concluded that in a certain range, mechanical vibration force may have accelerated tooth movement.

Keywords: Orthodontics; Canine Distalization; Vibration; Acceleration of Tooth Movement; Finite Element Analysis.

Cite This Article: Aylin Pasaoglu Bozkurt, and Alev Cinsar. (2018). "EFFECTS OF MECHANICAL VIBRATION FORCE ON TOOTH MOVEMENT; FINITE ELEMENT ANALYSIS." International Journal of Research - Granthaalayah, 6(1), 504-515. https://doi.org/10.29121/granthaalayah.v6.i1.2018.1671.

\section{Introduction}

Speed, aesthetics and technology are the most important concepts in the $21^{\text {st }}$ century. To meet the increasing demand of orthodontic treatment and to prevent root resorption, white spot lesions, caries, gingivitis, patients with loss of motivation, oral hygiene worsening and infections, 
treatment must be completed quickly and efficiently. ${ }^{1-5}$ Hence acceleration of tooth movement has gained popularity.

Orthodontic tooth movement is; displacement of a tooth in its bony socket from one place to another place as a result of alveolar resorption and formation at a certain time. ${ }^{6}$

It is necessary to affect the mechanical and biological components of the movement to accelerate it. Developed brackets and wires systems which are the mechanical components of movement have come to an advanced level and they reduce treatment time significantly as compared to the past. $^{7,8}$

Chemical injection, surgery, ultrasound, laser, electric current application methods are intended to affect the biological component of movements to accelerate tooth movement, by reducing the resistance around the periodontal tissue and changing environmental factors. ${ }^{7-10}$ One of the newly introduced methods is to use non-invasive, cyclical vibration forces to accelerate tooth movement in recent years. ${ }^{11-13}$

Studies conducted on the base of the skull and cranial sutures showed that cyclical force could create bone islands more effectively than static force, and vibration application could increase remodeling and gene regulation. ${ }^{14,15}$

Nishimura et al. showed that cyclical vibration force could increase RANKL value and accelerate the rate of tooth movement; with no damage on periodontal tissue in rats. ${ }^{11}$ Leethanakul et al. examined the secretion of interleukin (IL)-1b during tooth movement in vibration application. They determined that secretion and tooth movement were on higher levels on the side where vibration was applied. ${ }^{12}$ Pavlin et al. showed that low-level cyclical loading of $0.25 \mathrm{~N}$ at $30 \mathrm{~Hz}$ increased the rate of tooth movement when applied as an addition to orthodontic treatment. ${ }^{16}$

Besides proponents of vibration on acceleration tooth movement, there are also studies arguing that it has a slowing effect or have no effect at all. Disorderly organized fibers, reduced alveolar bone volume and slowed down the movement of tooth because of cyclical vibration force application were observed in the animal study which was done by Kalajzic at al. ${ }^{13}$

The animal study that investigated the effects of low frequency mechanical vibration force $(5,10,20 \mathrm{~Hz})$ by Nanda et al. and the randomized controlled clinical study about AcceleDent (30 $\mathrm{Hz}$ ) on tooth movement by Woodhouse et al. showed that vibration force had no significant acceleration effect. ${ }^{17,18}$ Miles et al., in their randomized controlled trial, showed that application of a $111 \mathrm{~Hz}$ vibration force for 20 minutes per day had no effect on acceleration of tooth movement. ${ }^{19}$ There is insufficient information about the biomechanical effects of mechanical cyclical vibration force on tooth movement.

Finite element analysis (FEA) is a useful mathematical instrument for orthodontics and it can determine the amount of stress, strain, and displacement in the dentoalveolar complex after different loading conditions of force. ${ }^{20}$ Hence the aim of this study was to determine the biomechanical effect of vibration force on tooth movement at canine distalization phase using 
FEM analysis, and compare the stress distribution between application of force only, and combined application of force and vibration.

\section{Materials and Methods}

A 20-year-old, non-syndromic male patient's CBCT (ILUMA, 3M Imtec, Oklahoma, USA) data, with the decision of extracting upper $1^{\text {st }}$ premolars because of orthodontic treatment, was used in this study. The principles outlined in the Declaration of Helsinki were followed.

CBCT DICOM data were obtained pre-operatively at 2-mm intervals to obtain geometric accuracy for modeling the maxilla. The DICOM data were imported into the 3D-DOCTOR (Able Software Corp., Massachusetts, USA) software and a 3D geometric model was constructed. For modelling the upper canine, model which was based on the anatomic information in Wheeler's "Textbook of Dental Anatomy and Physiology", made from plaster was used and it was scanned by Smart Optics (Activity 880, Bochum, Germany). Canine was modelled as homogeneous, not separating into enamel, dentin, pulp and cement layer. A 0.25 $\mathrm{mm}$ thick uniform structure of periodontal ligament (PDL) was obtained. ${ }^{21}$ Roth canine bracket (Ormco Corp., CA, USA) was scanned and placed on the center of the vestibule surface of canine.

Bone, tooth and bracket data were combined in Rhinoceros 4.0 (McNeel Inc., Seattle, WA, USA) software to obtain a common three-dimensional model. VRMesh Studio software (VirtualgridInc, Bellevue City, WA, USA) was used for regulation of the 3D network structure and to eliminate distorted sections. FEM analysis was performed using AlgorFempro (Algor Inc., USA) program.

Solid model consisted of bricks and tetrahedral elements. In the solid modeling system, all models were recognized as linear, homogeneous and isotropic materials. In our study, 147,942 tetrahedral elements and 34,410 nodes were used. Material properties were selected according to the literature and are shown in Table $1 .{ }^{22}$

Table 1: Material properties used in the finite element model analysis

\begin{tabular}{|c|c|c|}
\hline Material & Young's Modulus MPa & Poisson's Ratio \\
\hline Cortical bone & 13,700 & 0.3 \\
\hline Trabecular bone & 1370 & 0.3 \\
\hline Tooth (Dentin) & 18600 & 0.31 \\
\hline Periodontal ligament & 0,69 & 0.45 \\
\hline Bracket & 200 & 0.3 \\
\hline
\end{tabular}

Boundary conditions were defined at the upper region of maxilla which was away from force application point and the model was fixed to have zero movement at each degree of freedom. When force was applied to the model, it received support from these regions. Support planes should be chosen far away from the analysis sites (Figure 1). 


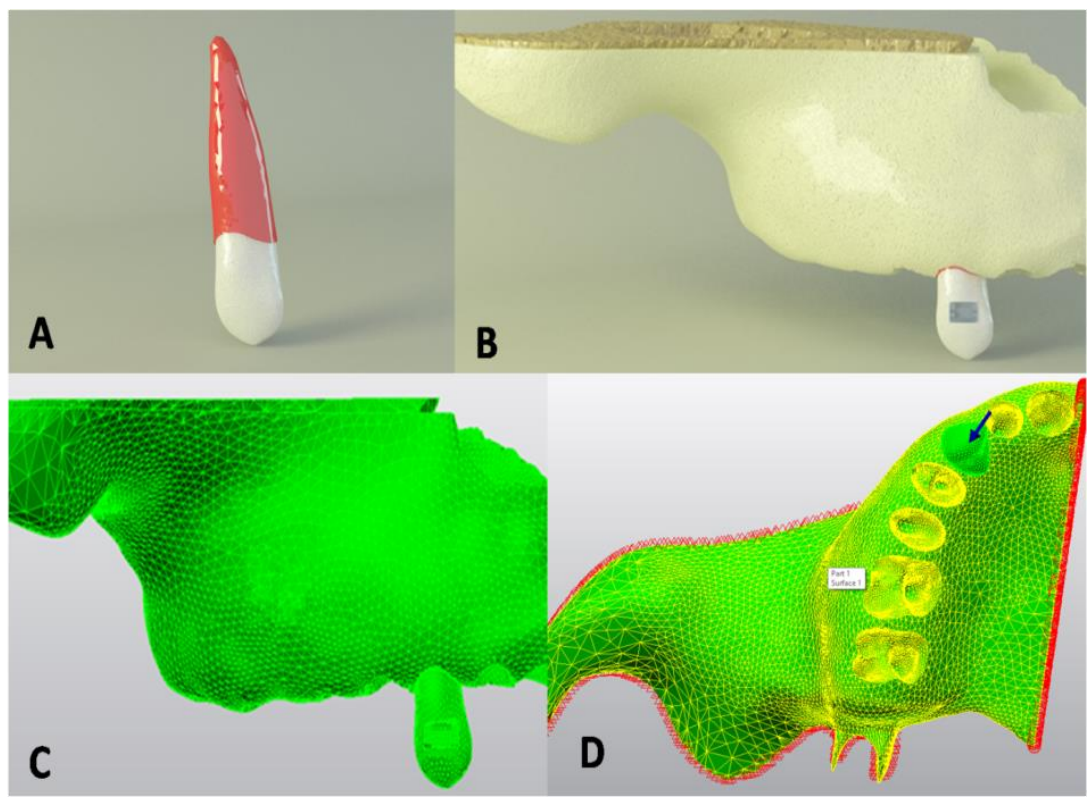

Figure 1.3D FEM of a patient with canine distalization. A)Modelling of tooth and PDL B) The model set which consisting of cortical bone, trabecular bone, tooth and bracket C) Network structure consisting of bricks and tetrahedral element D) Boundary conditions shown by red lines and the arrow shows the force direction

Three different FEA were carried out under different loading conditions on the same model. In the first analysis; a $150 \mathrm{~g}$ force (f) was applied to canine at bracket level from mesial to distal direction. In the second analysis, $150 \mathrm{~g}$ force (f) and $30 \mathrm{~Hz}$ vibration $(0.2 \mathrm{~N})$ and in the third analysis; $150 \mathrm{~g}$ force (f) and $111 \mathrm{~Hz}$ vibration $(0.06 \mathrm{~N})$, were applied by the 'Random Vibration Analysis' method. $150 \mathrm{gf}$ was applied in all analyzes from mesial to distal direction. Vibration force was applied on a wide surface of the canine crown (mesial, distal, buccal and palatal direction), not on a single point. $30 \mathrm{~Hz}$ and $111 \mathrm{~Hz}$ were chosen to compare stress and displacement values of clinical trials and research. ${ }^{18,19}$

Random vibration analysis is a linear analysis that is carried out using data from the natural frequency and power-spectral-density curve. These are representations of vibration frequencies and energy in a statistical form. The analysis determines displacement and stress distribution occurring per unit time. ${ }^{23}$ Measurements were made on mesial, distal, buccal and palatal surfaces of canine tooth socket both cortical and trabecular bone, and the maximum values of these measurements were taken into consideration.

Primary displacement pattern (sagittal, vertical, transversal), minimum and maximum principle stress level and Von misses stress distribution were analyzed undergoing force application only and application of both force and vibration, using FEM by linear static analysis.

\section{Results}

(Table 2) shows the 3D pattern of upper canine displacement; (Table 3) shows the stress distributions at maxillary bone around canine. 
Table 2: Three-dimensional (3D) pattern of canine displacements are shown by $\mathrm{mm}$

\begin{tabular}{|l|c|c|c|}
\hline Displacement value (mm) & $\mathbf{1 5 0}$ gf & $\mathbf{1 5 0}$ gf +30 Hz & $\mathbf{1 5 0}$ gf +111 Hz \\
\hline Crown level total displacement & 0.001030 & 0.002885 & 0.001787 \\
\hline Cervical level total displacement & 0.000627 & 0.001850 & 0.001167 \\
\hline Root apex level total displacement & 0.000061 & 0.000312 & 0.000648 \\
\hline $\mathrm{U}_{\mathrm{X}}$ Crown movement & -0.000444 & 0.000206 & 0.000769 \\
\hline $\mathrm{U}_{\mathrm{X}}$ Cervical movement & -0.000054 & 0.000270 & 0.000600 \\
\hline $\mathrm{U}_{\mathrm{X}}$ Root apex movement & 0.000020 & 0.000069 & 0.000182 \\
\hline $\mathrm{U}_{\mathrm{Y}}$ Crown movement & 0.000914 & 0.002822 & 0.001503 \\
\hline $\mathrm{U}_{\mathrm{Y}}$ Cervical movement & 0.000613 & 0.001816 & 0.000952 \\
\hline $\mathrm{U}_{\mathrm{Y}}$ Root apex movement & -0.000058 & 0.000282 & 0.000568 \\
\hline $\mathrm{U}_{\mathrm{Z}}$ Crown movement & -0.000168 & 0.000566 & 0.000584 \\
\hline $\mathrm{U}_{\mathrm{Z}}$ Cervical movement & 0.000123 & 0.000224 & 0.000310 \\
\hline $\mathrm{U}_{\mathrm{Z}}$ Root apex movement & $-2.954349 \mathrm{e}-006$ & 0.000116 & 0.000255 \\
\hline
\end{tabular}

Table 3: Three-dimensional (3D) pattern of stress distributions at maxillary bone around canine

\begin{tabular}{|l|c|c|c|c|}
\hline \multicolumn{1}{|c|}{ Bone stress distibution values } & $\begin{array}{c}\text { Tooth } \\
\text { surface }\end{array}$ & $\begin{array}{c}\mathbf{1 5 0} \\
\text { gf }\end{array}$ & $\begin{array}{c}\mathbf{1 5 0} \mathbf{g f + 3 0} \\
\mathbf{H z}\end{array}$ & $\begin{array}{c}\mathbf{1 5 0} \mathbf{g f + 1 1 1} \\
\mathbf{H z}\end{array}$ \\
\hline Max principle cortical bone values & Mesial & .062900 & 0.155340 & 0.080757 \\
\hline Max principle cortical bone values & Distal & 0.052771 & 0.147654 & 0.076761 \\
\hline Max principle cortical bone values & Buccal & 0.018374 & 0.234740 & 0.122035 \\
\hline Max principle cortical bone values & Palatal & 0.007224 & 0.174444 & 0.090689 \\
\hline Min principle cortical bone values & Mesial & -0.034171 & -0.107525 & -0.055899 \\
\hline Min principle cortical bone values & Distal & -0.063140 & -0.102802 & -0.053444 \\
\hline Min principle cortical bone values & Buccal & -0.093914 & -0.068584 & -0.035655 \\
\hline
\end{tabular}




\begin{tabular}{|l|c|c|c|c|}
\hline Min principle cortical bone values & Palatal & -0.095582 & -0.144310 & -0.075023 \\
\hline Max principle trabecular bone values & Mesial & 0.018496 & 0.033374 & 0.010687 \\
\hline Max principle trabecular bone values & Distal & 0.014015 & 0.012484 & 0.006490 \\
\hline Max principle trabecular bone values & Buccal & 0.008639 & 0.021861 & 0.010687 \\
\hline Max principle trabecular bone values & Palatal & 0.002097 & 0.051118 & 0.026575 \\
\hline Min principle trabecular bone values & Mesial & -0.008205 & -0.045881 & -0.023852 \\
\hline Min principle trabecular bone values & Distal & -0.006449 & -0.026721 & -0.013892 \\
\hline Min principle trabecular bone values & Buccal & -0.006312 & -0.023551 & -0.013114 \\
\hline Min principle trabecular bone values & Palatal & -0.008177 & -0.013468 & -0.013892 \\
\hline
\end{tabular}

Displacement and stress distributions of the canine and the bone structure around canine are shown in (Figures 2-3).

Displacements in the Transverse Plane $\left(U_{x}\right)$

$\mathrm{X}$-axis represents the palatal direction displacement on the model (Figure 2(A)). When evaluating $U_{x}$ only, maximum movement occurred in the $3^{\text {rd }}$ analysis.

Displacements in the Sagittal Plane $\left(\mathrm{U}_{\mathbf{y}}\right)$

Y-axis represents the distal direction displacement on the model (Figure 2(B)). Primary force application caused tipping in three analyses. While evaluating Uy only, maximum crown and cingulum movement occurred in the $2^{\text {nd }}$ analysis, and maximum apex movement was in the $3^{\text {rd }}$ analysis.

Displacements in the Vertical Plane $\left(\mathbf{U}_{\mathrm{z}}\right)$

Z-axis represents the sulcus direction displacement on the model (Figure 2(C)). While evaluating $\mathrm{U}_{\mathrm{z}}$ only, maximum crown, cingulum and apex displacement occurred in the $3^{\text {rd }}$ analysis. While force application by itself caused extrusion, application of force and vibration together caused intrusion.

\section{Total Displacement Values}

When evaluating total displacement, maximum movement occurred while applying force and 30 $\mathrm{Hz}$ vibration $\left(2^{\text {nd }}\right.$ analysis $)$, while less movement occurred while applying force only $\left(1^{\text {st }}\right.$ analysis) (Figure 2(D, E)).

\section{Minimum - Maximum Principle Stress Values}

Maximum compressive and tensile values were analyzed separately for both cortical and trabecular bone layers. 


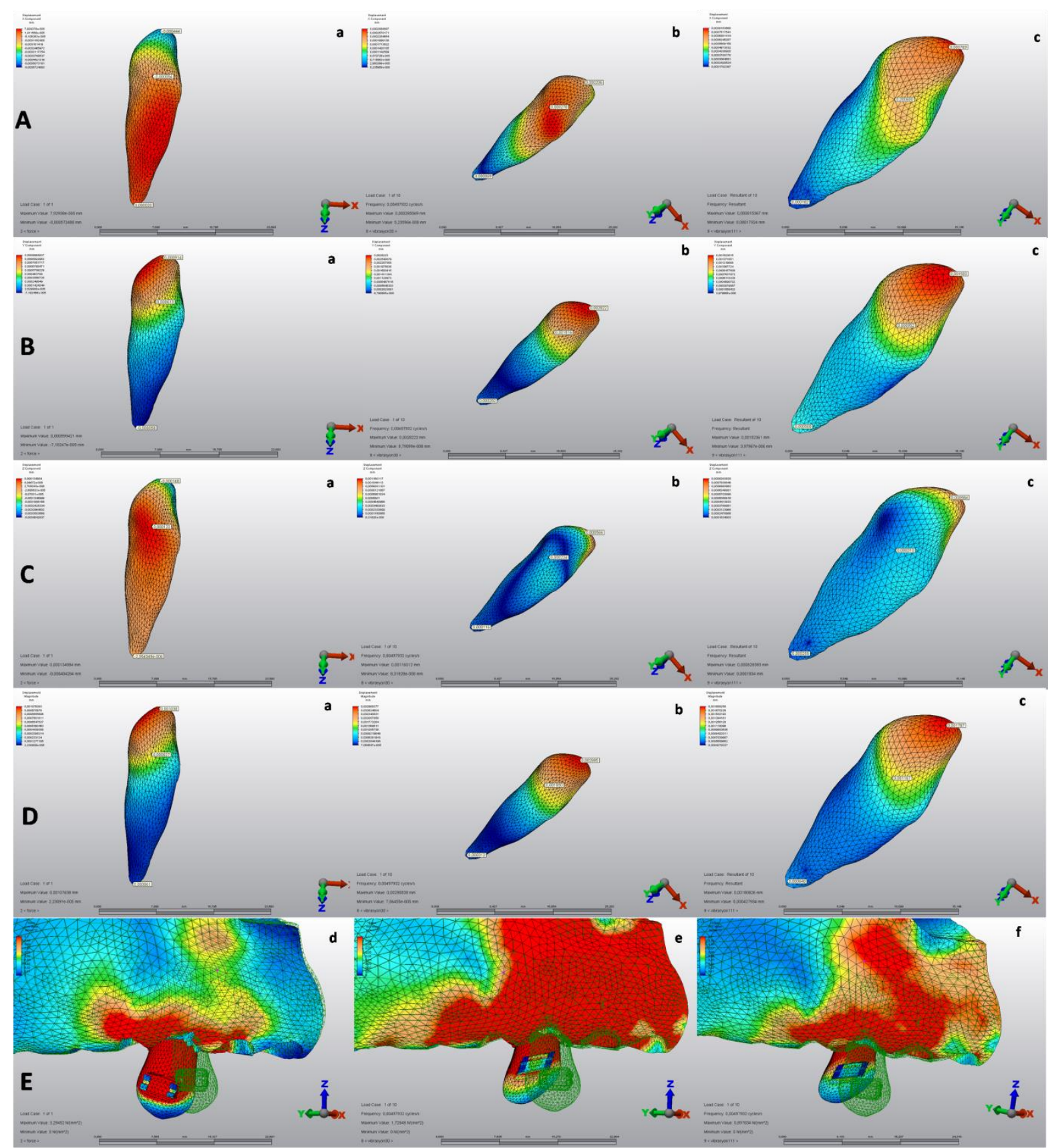

Figure 2: (A) Transversal displacement values of canine at $150 \mathrm{gf}$ (a), $150 \mathrm{gf}-30 \mathrm{~Hz}$ vibration (b), $150 \mathrm{gf}-111 \mathrm{~Hz}$ vibration (c). (B) Sagittal displacement values of canine at $150 \mathrm{gf}$ (a), $150 \mathrm{gf}$ - $30 \mathrm{~Hz}$ vibration (b), $150 \mathrm{gf}-111 \mathrm{~Hz}$ vibration (c). (C) Vertical displacement values of canine at $150 \mathrm{gf}$ (a), $150 \mathrm{gf}-30 \mathrm{~Hz}$ vibration (b), $150 \mathrm{gf}-111 \mathrm{~Hz}$ vibration (c). (D)Total displacement values of canine at $150 \mathrm{gf}(\mathrm{a}, \mathrm{d}), 150 \mathrm{gf}-30 \mathrm{~Hz}$ vibration (b,e), $150 \mathrm{gf}-111 \mathrm{~Hz}$ vibration (c,f) and (E) superimposition data before and after force application (d,e,f). 

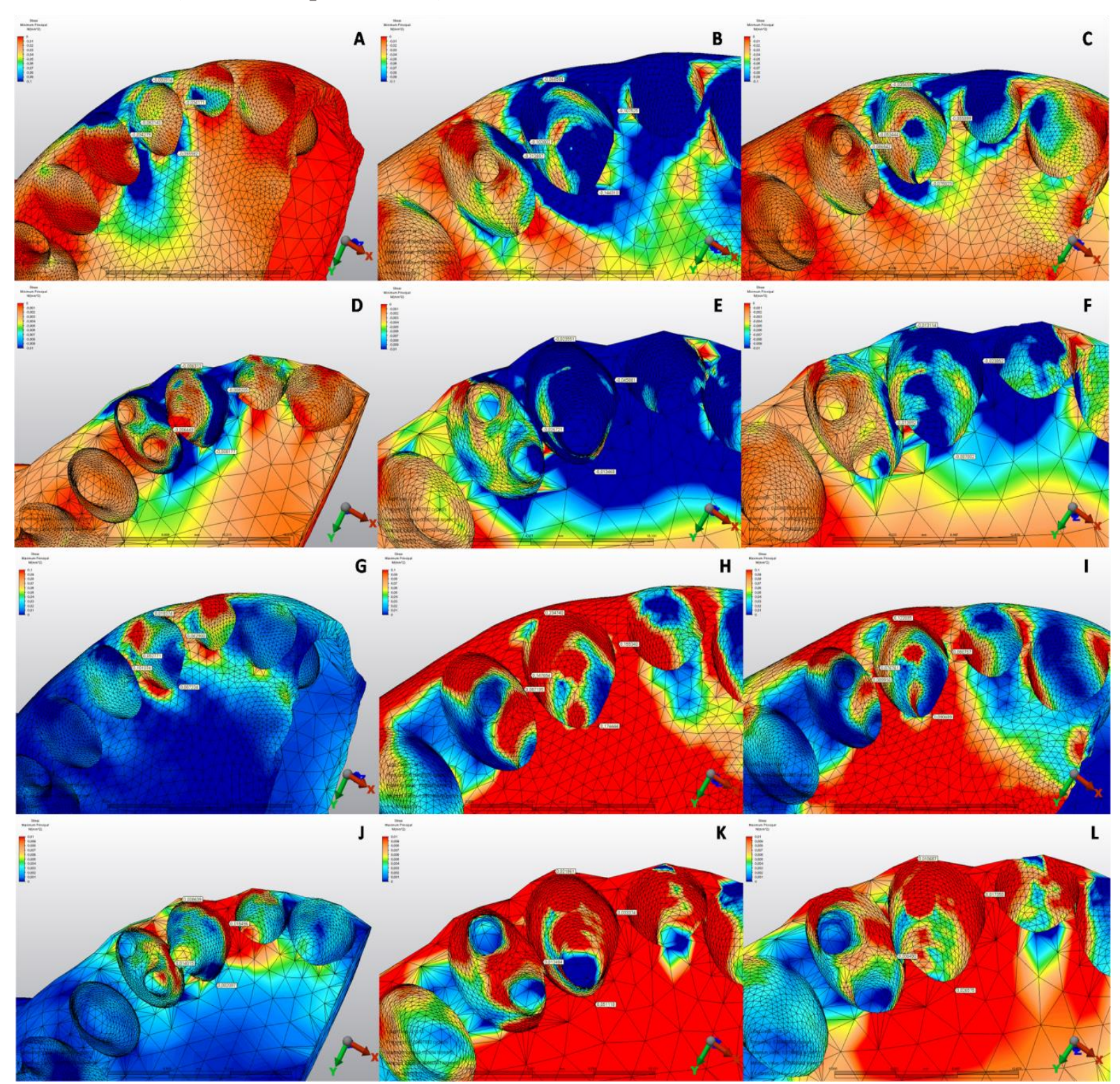

Figure 3: Minimum principle cortical $(\mathrm{A}, \mathrm{B}, \mathrm{C}$,$) and trabecular (\mathrm{D}, \mathrm{E}, \mathrm{F})$ bone values around canine at $150 \mathrm{gf}(\mathrm{A}, \mathrm{D}), 150 \mathrm{gf}-30 \mathrm{~Hz}$ vibration $(\mathrm{B}, \mathrm{E}), 150 \mathrm{gf}-111 \mathrm{~Hz}$ vibration $(\mathrm{C}, \mathrm{F})$. Maximum principle cortical $(\mathrm{G}, \mathrm{H}, \mathrm{I})$ and trabecular $(\mathrm{J}, \mathrm{K}, \mathrm{L})$ bone values around canine at $150 \mathrm{gf}(\mathrm{G}, \mathrm{J})$, $150 \mathrm{gf}-30 \mathrm{~Hz}$ vibration $(\mathrm{H}, \mathrm{K}), 150 \mathrm{gf}-111 \mathrm{~Hz}$ vibration (I, L)

\section{Cortical bone}

Maximum compression level (minimum principle values) had highest value at distal $(-0.102802$ $\left.\mathrm{N} / \mathrm{mm}^{2}\right)$ and palatal $\left(-0.144310 \mathrm{~N} / \mathrm{mm}^{2}\right)$ surfaces of canine tooth on maxillary cortical bone in the $2^{\text {nd }}$ analysis (Figure 3 ).

In the $2^{\text {nd }}$ and $3^{\text {rd }}$ analyses, maximum tensile stress value (maximum principle values) of the cortical bone around the tooth for each surface layer was found to be higher than it was in the $1^{\text {st }}$ analysis. These values were higher than those in the $2^{\text {nd }}$ and $3^{\text {rd }}$ analyses. The highest values were obtained in the $2^{\text {nd }}$ analysis of the masial side of canine $\left(0.155340 \mathrm{~N} / \mathrm{mm}^{2}\right)$ (Figure 3$)$. 


\section{Trabecular bone}

The maximum compression values for cancellous bone layer were on the highest level in the $2^{\text {nd }}$ analysis. Those in the $3^{\text {rd }}$ analysis were found to be higher than those in the $1^{\text {st }}$.

It was seen that if a place showed a high stress level, minimum principal stress values were also higher. In the $2^{\text {nd }}$ analysis, where an application of $30 \mathrm{~Hz}$ vibration was made, stress accumulation in the distal surface of canine $\left(-0.026721 \mathrm{~N} / \mathrm{mm}^{2}\right)$ was higher. In this region, this means more bone resorption may occur (Figure 3).

The maximum principle value was obtained in the mesial trabecular layer of canine in the $2^{\text {nd }}$ analysis $\left(0.033374 \mathrm{~N} / \mathrm{mm}^{2}\right)$. Maximum tensile level on all surfaces except the distal surface of canine was greatest in the $2^{\text {nd }}$ analysis (Figure 3 ).

Vibration applications increased tensile values on the cortical bone and compression values on the trabecular bone in contrast to the application of force only.

\section{Von Mises Stress Distribution}

Von Mises value shows density and distribution of the stress level. Stress levels occurred around the canine on maxillary bone and at the cingulum level of the tooth. The highest stress levels were observed in the $2^{\text {nd }}$ analysis (Figure 4 ).

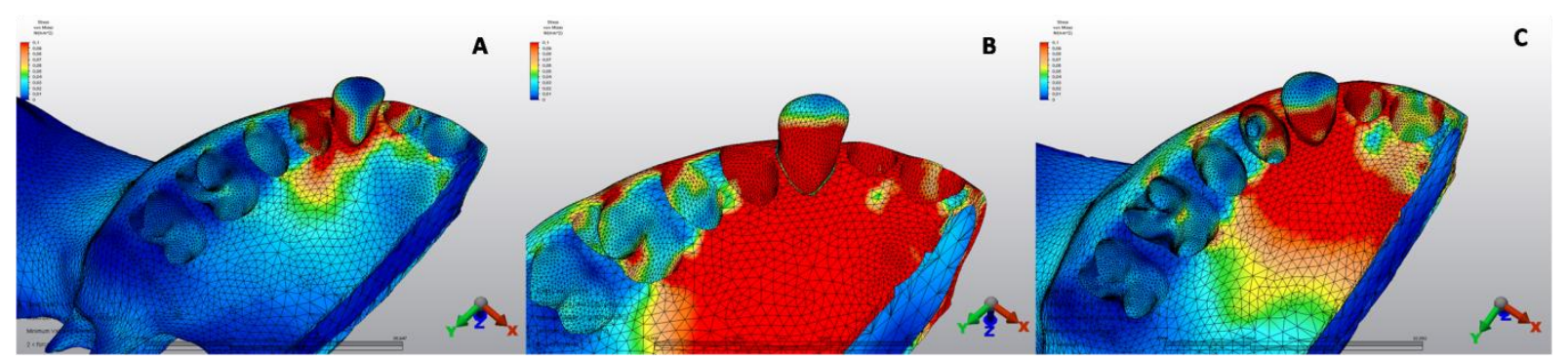

Figure 4.Von Mises stress distribution of canine at $150 \mathrm{gf}(\mathrm{A}), 150 \mathrm{gf}-30 \mathrm{~Hz}$ vibration (B), 150 gf $111 \mathrm{~Hz}$ vibrations (C)

\section{Discussion}

In this study, three FEAs were done which simulated two different vibration interventions and a conventional force application for canine retraction. Although many clinical and animal research studies have been published about accelerated tooth movement effects of vibration, there is no article has compared the biomechanical effects on tooth and surrounding tissues.

Canine distalization is the most commonly used method to evaluate tooth movement. Many force values were used to examine the movement of canines in different studies ${ }^{6}$ so biologically most suitable force of $150 \mathrm{~g}$ was chosen for canine retraction. ${ }^{24}$

There are many methods to accelerate tooth movement by activating remodeling process and many studies have been conducted on these methods. ${ }^{8,10,25}$ Application of a cyclical vibration force is one of these methods. There have been in vivo and in vitro studies which investigated the impact of mechanical vibration force on bone modeling and accelerating tooth movement. Some 
of these studies showed a positive effect of vibration ${ }^{11,12,14,15}$ and some argued for a negative effect or no significant effect at all ${ }^{13,18,19}$.

The real impact of cyclical vibration force on acceleration of tooth movement may not be determined clearly by in vivo studies because of ethical problems, dependence of usage by the patient and unknown biological effects on tissues. For this reason, an in vitro method was chosen to evaluate the real impact of vibration on movement. $30 \mathrm{~Hz}{ }^{13,16,18}$ and $111 \mathrm{~Hz}^{19}$ values were selected to evaluate the effects of low and high amounts of vibration on movement.

Guo et al.found that loading cyclical vibrational force could affect bone tissue and could be potentially harmful if applied in excess level, in the nonlinear FEA study conducted on L3-L5 lumbar vertebrae. ${ }^{26}$ Christiansen et al. reported that vibrational force could stimulate new trabecular bone formation and $60-70 \mathrm{~Hz}$ gave the best result. ${ }^{27}$ The vibration forces in certain values may affect the bone tissue as it is in our work.

Elements constructed based on the complex geometry of the body are generally in a tetrahedral shape. Gautam et al.reported that tetrahedral elements are ideal for human teeth and surrounding tissues' characteristics. ${ }^{28}$ Bricks-tetrahedral elements were used in this study.

Structures in the model were accepted as homogeneous, isotropic and linear elastic in our study. The results obtained from generalization in this study will slightly vary from the reality. We believe that it is appropriate from a scientific point of view, because mechanical properties of materials and the amount of force used were kept constant and the model analyses were evaluated in relation to each other. Since there were no previous studies found evaluating the acceleration effect of vibration on tooth movement using the FEA method, findings were discussed as a whole and in comparison to each other.

Only force application's minimum principle compression values and locations for trabecular and cortical bone were similar in the study by Kojiama et al. ${ }^{29,30}$ When vibration was applied, the variation of stress distribution changed. More stress accumulation at the distal surface of canine was seen in the $2^{\text {nd }}$ analysis which means that more bone resorption may occur. Vibration applications increased the tension values in cortical bone and the compression values in trabecular bone, in contrast to the results of applying force only.

The FEA study which was done by Xue et al. found that non-surgical canine distalization showed the slowest movement. ${ }^{22}$ the data were consistent with our study in the sagittal direction. Examining the amount of canine movement, application of $30 \mathrm{~Hz}$ vibration showed more movement. This finding is consistent with findings of studies claiming vibration accelerates tooth movement. ${ }^{11,12,14,15}$ this study also complies with clinical studies showing that cyclical vibration forces are effective on accelerating and stimulating tooth movements.12, 16

While evaluating the amount of movement, the application of $111 \mathrm{~Hz}$ showed more movement than the application of force only, but less movement than the application with $30 \mathrm{~Hz}$. This finding is incompatible with the study which used the same vibration value. ${ }^{19}$ 
Low vibration values have higher stimulation effects on movement, which may be related to closeness to the natural frequency value of canine; however, this subject needs further research. The limitation of this study is only to have examined the movement of canine and certain vibration values effects.

\section{Conclusions}

According to total displacement values, it was concluded that specific ranges of mechanical vibration force $(30 \mathrm{~Hz})$ may have accelerated tooth movement.

Vibration force application may influence the rate of tooth movement by affecting tension and compression values of cortical and cancellous bone layers.

It is thought that application of static and cyclical force together is more effective on tooth movement acceleration than application of static force only.

\section{References}

[1] Geiger AM, Gorelick L, Gwinnett AJ, Benson BJ. Reducing white spot lesions in orthodontic populations with fluoride rinsing. Am J Orthod Dentofacial Orthop. 1992; 101:403-7.

[2] Bishara SE, Ostby AW. White spot lesions: formation, prevention, and treatment. Semin Orthod. 2008; 14:174-82.

[3] Segal GR, Schiffman PH, Tuncay OC. Meta analysis of the treatment-related factors of external apical root resorption. Orthod Craniofac Res. 2004; 7:71-8.

[4] Pandis N, Nasika M, Polychronopoulou A, Eliades T.External apical root resorption in patients treated with conventional and self-ligating brackets. Am J Orthod Dentofacial Orthop. 2008; 134:646-51.

[5] Royko A, Denes Z, Razouk G. The relationship between the length of orthodontic treatment and patient compliance. Fogorv Sz. 1999; 92:79-86.

[6] Thilander B, Rygh P, Kaare R. Tissue Reactions in Orthodontics. In: Thomas M.Graber, Vanarsdall RL, and Orthodontics: Current Principles and Techniques. St. Louis Mosby, Inc., 2000, 117-91.

[7] Krishnan V, Davidovitch Z. Cellular, molecular, and tissue-level reactions to orthodontic force. Am J Orthod Dentofacial Orthop, 2006; Apr; 129(4):469.e1-32.

[8] Gkantidis N, Mistakidis I, Kouskoura T, Pandis N. Effectiveness of non-conventional methods for accelerated orthodontic tooth movement: A systematic review and meta-analysis. J Dent. 2014 Oct; 42(10):1300-19.

[9] Nimeri G, Kau CH, Abou-Kheir NS, Corona R. Acceleration of tooth movement during orthodontic treatment - a frontier in Orthodontics. Prog Orthod. 2013 Oct 29; 14:42. doi: 10.1186/2196-1042-14-42.

[10] Long H, Pyakurel U, Wang Y, Liao L, Zhou Y, Lai W. Interventions for accelerating orthodontic tooth movement A systematic review. Angle Orthod. 2013; 83:164-71.

[11] Nishimura M, Chiba M, Ohashi T, Sato M, Shimizu Y, and Igarashi K, Mitanig H. Periodontal tissue activation by vibration: Intermittent stimulation by resonance vibration accelerates experimental tooth movement in rats. Am J Orthod Dentofacial Orthop 2008; 133:572-83.

[12] Leethanakul C, Suamphan S, Jitpukdeebodintra S, Thongudomporn U, Charoemratrote C. Vibratory stimulation increases interleukin-1 beta secretion during orthodontic tooth movement. Angle Orthod. 2016 Jan;86(1):74-80. 
[13] Kalajzic Z, Peluso EB, Utreja A, Dyment N, Nihara J, Xu M, Cheng J, Uribe F, Wadhwa S. Effect of cyclical forces on the periodontal ligament and alveolar bone remodeling during orthodontic tooth movement. Angle Orthod. 2014; 84: 297-303.

[14] Peptan AI, Lopez A, Kopher RA, Mao JJ. Responses of intramembranous bone and sutures upon in vivo cyclic tensile and compressive loading. Bone. 2008 Feb; 42(2):432-8.

[15] Mao JJ, Wang X, Mooney MP, et al. Strain induced osteogenesis in the craniofacial suture upon controlled delivery of low-frequency cyclic forces. Front Biosc. 2003; 8:a10-7.

[16] Pavlin D, Anthony R, Raj V, Gakunga P.Cyclic loading (vibration) accelerates tooth movement in orthodontic patients: A double-blind, randomized controlled trial. (Semin Orthod 2015; 21:187-94.

[17] Yadav S, Dobie T, Assefnia A, Gupta H, Kalajzic Z, Nanda R. Effect of low-frequency mechanical vibration on orthodontic tooth movement. Am J Orthod Dentofacial Orthop. 2015 Sep; 148(3):440-9.

[18] Woodhouse NR, DiBiase AT, Johnson N, Slipper C, Grant J, Alsaleh M, Donaldson AN, Cobourne MT. Supplemental vibrational force during orthodontic alignment: a randomized trial. J Dent Res. 2015 May; 94(5):682-9.

[19] Miles P, Smith H, Weyant R, Rinchuse DJ. The effects of a vibrational appliance on tooth movement and patient discomfort: a prospective randomised clinical trial, Aust Orthod J 2012; 28: 213-8.

[20] Bai D, Cheng BH, Luo SJ, Lü T. Three-dimensional finite element analysis of maxillary canine during the tooth translation movement. Sichuan Da Xue Xue Bao Yi Xue Ban. 2004; 35:358-60.

[21] Cai Y, Yang X, He B, Yao J. Finite element method analysis of the periodontal ligament in mandibular canine movement with transparent tooth correction treatment. BMC Oral Health. 2015 Sep 4; 15:106.

[22] Xue J, Ye N, Yang X, Wang S, Wang J, Wang Y, Li J, Mi C, Lai W. Finite element analysis of rapid canine retraction through reducing resistance and distraction. J Appl Oral Sci. 2014 JanFeb; 22(1):52-60.

[23] http://knowledge.autodesk.com/support/simulationmechanical/learnexplore/caas/CloudHelp/clou dhelp/2015/ENU/SimMech/files/GUID-04474C1B-394D-46CD-8500-D50A1A0011F3htm.html.

[24] Proffit WR, Fields HW, Sarver DM. Contemporary Orthodontics, St. Louis, 2007 Mosby, Inc.

[25] Hoogeveen EJ, Jansma J, Ren Y. Surgically facilitated orthodontic treatment: a systematic review. Am J Orthod Dentofacial Orthop 2014 Apr; 145:S51-64.

[26] Guo LX, Teo EC, Lee KK, Zhang QH. Vibration characteristics of the human spine under axial cyclic loads: effect of frequency and damping.Spine(Phila Pa 1976). 2005 Mar 15; 30(6):631-7.

[27] Christiansen BA, Bayly PV, Silva MJ, Constrained tibial vibration in mice: a method for studying the effects of vibrational loading of bone. J Biomech Eng. 2008 Aug; 130(4):044502. doi: $10.1115 / 1.2917435$.

[28] Gautam P, Valiathan A, Adhikari R. Craniofacial displacement in response to varying headgear forces evaluated biomechanically with finite element analysis. Am J Orthod Dentofacial Orthop 2009; 135:507-15.

[29] Kojima Y, Kawamura J, Fukui H. Finite element analysis of the effect of force directions on tooth movement in extraction space closure with miniscrew sliding mechanics. Am J Orthod Dentofacial Orthop. 2012 Oct; 142(4):501-8.

[30] Kojima Y, Fukui H. Numerical simulation of canin retraction by sliding mechanics. Am J Orthod Dentofacial Orthop 2005; 127:542-51.

\footnotetext{
*Corresponding author.

E-mail address: pasaylin@ hotmail.com
} 